\title{
SUPERCHANNEL SEBAGAI METODE CEPAT DALAM MENGATASI INTERFERENSI FREKUENSI 2,4 GHz
}

\author{
Sutiyo \\ Jurusan Teknik Elektro, Fakultas Teknik, Universitas Widya Dharma Klaten \\ Jl. K.H. Dewantara, Klaten Utara, Klaten \\ email: tio@unwidha.ac.id
}

\begin{abstract}
As a result of the release of ISM $2.4 \mathrm{GHz}$ frequency for use in the field of wireless data communication through the media and the lack of clarity about the rules in the use of a frequency of $2.4 \mathrm{GHz}$ to be one factor interference in wireless communication. Interference generally occurs in urban areas the level of use of wireless data communication through the media is very high. Wireless devices $2.4 \mathrm{GHz}$ are easily available and inexpensive, making the user media data communications using wireless LAN as a cheap alternative compared to other data communication media, such as Fiber Optic, Radio Microwave Link.

It is in fact the channel that is used in $2.4 \mathrm{GHz}$ wireless communication is permitted only 11 channels starting from 2412Mhz-2462Mhz frequency, as more users make a frequency of $2.4 \mathrm{GHz}$ increasingly crowded existing channels, resulting in wide bandwidth of each channel is also increasingly cramped. The width of the narrow bandwidth that clearly affects the quality of the process data communication, data sent or received experienced loss.

One quick method to overcome these problems is to utilize the capabilities of wireless devices Superchannel. One of the wireless devices with Atheros AR5413 chipset which has a mini-PCl Superchannel is $\mathrm{R} 52 \mathrm{H}$ which is the product of mikrotik. Superchannel frequency range starting from 2192Mhz - 2539Mhz. Indeed, in the frequency range is still illegal superchannel for some countries, like Indonesia, but many Internet access providers, or ISPs use this superchannel capabilities for data communication media, both for distribution to customers or to the ISP backbone network, although not used permanently.
\end{abstract}

\section{Keywords : Network, Wireless, ISM, 2.4Ghz, Bandwidth, Superchannel, Interference}

Sebagai akibat dari pembebasan frekuensi ISM 2,4 Ghz untuk digunakan dalam bidang komunikasi data melewati media wireless dan tidak jelasnya aturan main dalam penggunaan frekuensi 2,4 Ghz menjadi salah satu faktor interference dalam komunikasi wireless. Interference umumnya terjadi di daerah perkotaan yang tingkat penggunaan komunikasi data lewat media wireless sangat tinggi. Perangkat-perangkat wireless $2,4 \mathrm{GHz}$ yang mudah didapat dan murah, menjadikan para pengguna media komunikasi data menggunakan wireless LAN sebagai alternative murah dibandingkan media komunikasi data lain, semisal Fiber Optic, Radio Link Microwave.

Memang pada kenyataannya channel yang digunakan dalam komunikasi wireless 2,4 Ghz yang diijinkan ini hanya 11 channel dimulai dari frekuensi 2412Mhz-2462Mhz, dengan semakin banyaknya pengguna frekuensi $2,4 \mathrm{Ghz}$ membuat semakin padat channel-channel yang ada, akibatnya lebar bandwidth setiap channel juga semakin sempit. Lebar bandwidth yang semakin sempit jelas mempengaruhi kualitas dari proses komunikasi data, data yang dikirim atau diterima mengalami loss.

Salah satu metode cepat untuk mengatasi masalah tersebut adalah dengan memanfaatkan kemampuan Superchannel dari perangkat wireless. Salah satu perangkat wireless dengan chipset Atheros AR5413 yang memiliki Superchannel adalah mini-PCl R52H yang merupakan produk dari mikrotik. Rentang frekuensi Superchannel mulai dari 2192Mhz 2539Mhz. Memang rentang frekuensi dalam superchannel ini masih illegal untuk beberapa negara, seperti Indonesia, tetapi banyak penyedia jasa akses internet atau ISP menggunakan kemampuan superchannel ini untuk media komunikasi data, baik untuk distribusi ke pelanggan atau untuk jaringan backbone ISP walaupun tidak digunakan secara permanen.

Kata Kunci : Network, Wireless, ISM, 2.4Ghz, Bandwidth, Superchannel, Interference 


\section{PENDAHULUAN}

Internet menjadi media yang sangat pesat perkembangannya dalam sepuluh tahun terakhir ini bukan hanya di dunia, tetapi juga di Indonesia. Pesatnya perkembangan Internet tersebut juga didukung dengan semakin relatif murahnya perangkat telekomunikasi sebagai teknologi pendukungnya, serta makin mudah dijangkau oleh masyarakat umum.

Bukan hanya perangkat yang berbasis teknologi kabel (wired technology), namun juga perangkat yang berbasis teknologi nirkabel (wireless technology). Bahkan karena kemudahan instalasi dan fleksibelitas penggunaannya, perangkat berbasis teknologi nirkabel kemudian menjadi lebih disukai.

Meski demikian, keharusan adanya izin penggunaan suatu bidang frekuensi bagi perangkat nirkabel agak menghambat pemanfaatan teknologi ini di kalangan masyarakat umum. Hingga beberapa tahun lalu, hal tersebut merupakan isu yang paling banyak dibicarakan oleh masyarakat pengguna jaringan nirkabel di Indonesia.

Oleh karenanya, munculnya kebijakan pemerintah pada tahun 2005 yang "membebaskan" izin penggunaan bidang frekuensi $2,4 \mathrm{GHz}$ untuk keperluan akses Internet nirkabel dinilai sangat positif bagi perkembangan akses Internet, khususnya akses nirkabel, oleh masyarakat umum.

Namun di sisi lain, perkembangan akses Internet nirkabel di bidang fekuensi 2,4 GHz yang sangat pesat menyebabkan bidang frekuensi tersebut padat pemanfaatannya, terutama di kotakota besar (Taba, 2004). Padatnya bidang frekuensi tersebut disinyalir merupakan penyebab utama lambatnya akses Internet nirkabel pada jam-jam tertentu.

Di samping itu, karena bebasnya penggunaan perangkat-perangkat nirkabel yang menggunakan bidang frekuensi $2,4 \mathrm{GHz}$, pada prakteknya sering terjadi interferensi di tempattempat yang padat oleh penggunaan perangkat nirkabel tersebut (Taba, 2004). Hal tersebut disinyalir akibat dari penggunaan perangkat yang tidak disertifikasi, maupun perangkat yang melanggar batas daya pancar.

Bahkan ditemukan adanya iklan di Internet yang menawarkan penguat WLAN (WLAN amplifier) untuk meningkatkan daya pancar hingga 10 Watt bahkan 20 Watt (Amal, 2005). Ada beberapa Internet Service Provider (ISP) di kota-kota besar yang menggunakan penguat ini sehingga dapat memicu gangguan terhadap pengguna lain, dikarenakan lebar band yang semakin sempit.

Sehingga dengan penelitian yang penulis lakukan, mampu memberikan kontribusi kepada semua pihak yang berkepentingan dalam memanfaatkan frekuensi khususnya frekuensi ISM agar menggunakan free resource dengan baik dan diharapkan mampu meminimalkan interferensi.

Terdapat beberapa penelitian yang telah dilakukan terkait dengan interferensi frekuensi 2,4 $\mathrm{GHz}$, diantaranya :

1) Minimize WLAN interference. (Geier, 2004), membahas interferensi dari beberapa perangkat 2,4 Ghz, diantaranya WLAN, Bluetooth, Microwave. Dimana interferensi dari beberapa resource tersebut akan berimbas pada kualitas WLAN.

2) Ensuring WLAN, Bluetooth Coexistence. (Prince, 2005), membahas mitigasi dari perangkat Bluetooth yang interferensi dengan pernagkat WLAN.

3) Avoiding Interference in the 2.4-GHz ISM Band (Gerrior, Ryan, 2005), peneliti memberikan solusi untuk menghindari gangguan dari frekuensi 2,4 Ghz, terutama bagaimana membangun protocol sendiri dari setiap perangkat yang bekerja pada 2,4 $\mathrm{GHz}$.

4) When DSSS and FHSS fail: Avoiding interference on the 2.4GHz. (Bonnerud, 2007), membahas bagaimana strategi menghindari gangguan pada $2,4 \mathrm{GHz}$, ketika DSSS dan FHSS mengalami gangguan.

5) Interference Identification. (Metageek, 2009), membahas cara untuk melakukan analisa secara grafis dari frekuensi 2,4 Ghz. 
Dalam penelitian ini, penulis telah melakukan beberapa observasi atau pengamatan langsung khususnya dalam penggunaan frekuensi 2,4 Ghz untuk perangkat WLAN. Dengan beberapa bantuan perangkat analisa frekuensi seperti 2,4Ghz Spectrum Analyzer, Wireless Analysis yang disediakan oleh Mikrotik dalam Winbox.

\section{FREKUENSI $2,4 \mathrm{GHz}$}

Frekuensi merupakan sumber daya (resource) yang sangat penting pada telekomunikasi nirkabel. Oleh karena itu, penggunaan frekuensi perlu ditata agar dapat bermanfaat secara lebih efisien dan optimal. Pengaturan penggunaan frekuensi tersebut diatur secara internasional melalui Radio Regulation ITU (International Telecommunication Union) maupun secara nasional melalui Direktorat Jenderal Pos dan Telekomunikasi, yang sekarang menjadi bagian dari Departemen Komunikasi dan Informatika Republik Indonesia. Perangkat-perangkat yang menggunakan frekuensi 2,4 Ghz, diantaranya :
1) Wi-Fi atau WLAN
2) Bluetooth
3) Wireless USB
4) Zigbee
5) Cordless Phone $2.4 \mathrm{GHz}$

\section{WiFi}

Ada dua metode untuk modulasi frekuensi radio di 2,4 GHz yaitufrekuensi-hopping spread spectrum (FHSS) dan direct-sequence spread spectrum (DSSS). Bluetooth menggunakan sistem FHSS sementara Wireless USB, WiFi dengan protocol $802.11 \mathrm{~b} / \mathrm{g} / \mathrm{a}$ dan protocol 802.15.4 yang dikenal sebagai ZigBee menggunakan DSSS. Semua teknologi ini beroperasi di pita frekuensi ISM $(2.400-2.483 \mathrm{GHz})$. Perbandingan sinyal yang beroperasi pada band 2.4 Ghz terlihat seperti pada gambar 1 .

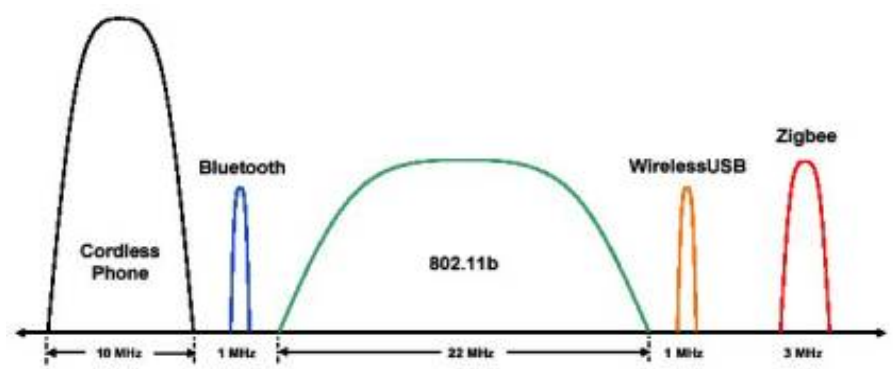

Gambar 1. Perbandingan sinyal sistem nirkabel yang beroperasi di band 2.4-GHz.

Motivasi utama dalam menggunakan Wi-Fi adalah throughput datanya.Wi-Fi menggunakan DSSS, dengan masing-masing saluran mempunyai lebar band $22 \mathrm{MHz}$, dan terdistribusi menjadi 3 saluran yang sama untuk digunakan secara bersamaan tanpa tumpang tindih satu dengan yang lain. Saluran yang digunakan oleh setiap Wi-Fi harus dikonfigurasi secara manual. Perbandingan data rate, banyaknya channel, kemudian metode penanganan interferensi terlihat pada tabel 1 berikut.

Tabel 1. Perbandingan teknologi $2,4 \mathrm{Ghz}$. 


\begin{tabular}{|c|l|l|l|l|}
\hline & \multicolumn{5}{|c|}{$2.4 \mathrm{GHz}$ Technology Comparison } \\
\hline & Data Rate & \multicolumn{1}{|c|}{$\begin{array}{c}\text { Number of } \\
\text { channels }\end{array}$} & $\begin{array}{l}\text { Interference } \\
\text { Avoidance } \\
\text { Method }\end{array}$ & $\begin{array}{c}\text { Minimum } \\
\text { Quiet } \\
\text { Bandwidth } \\
\text { Required }\end{array}$ \\
\hline $\begin{array}{c}\text { Wi-Fi } \\
\text { (802.11b) }\end{array}$ & $11 \mathrm{Mbps}$ & 13 & $\begin{array}{l}\text { Fixed channel } \\
\text { collision } \\
\text { avoidance }\end{array}$ & $\begin{array}{l}22 \mathrm{MHz} \\
\text { (Static) }\end{array}$ \\
\hline Bluetooth & $723 \mathrm{Kbps}$ & 79 & $\begin{array}{l}\text { Adaptive } \\
\text { frequency } \\
\text { hopping }\end{array}$ & $\begin{array}{l}15 \mathrm{MHz} \\
\text { (Dynamic) }\end{array}$ \\
\hline WirelessUSB & $62.5 \mathrm{Kbps}$ & 79 & $\begin{array}{l}\text { Frequency } \\
\text { agility }\end{array}$ & $\begin{array}{l}1 \mathrm{MHz} \\
\text { (Dynamic) }\end{array}$ \\
\hline Zigbee & $128 \mathrm{Kbps}$ & 16 & $\begin{array}{l}\text { Fixed channel } \\
\text { collision } \\
\text { avoidance }\end{array}$ & $3 \mathrm{MHz}$ (Static) \\
\hline
\end{tabular}

\section{PERBANDINGAN FHSS dan DSSS}

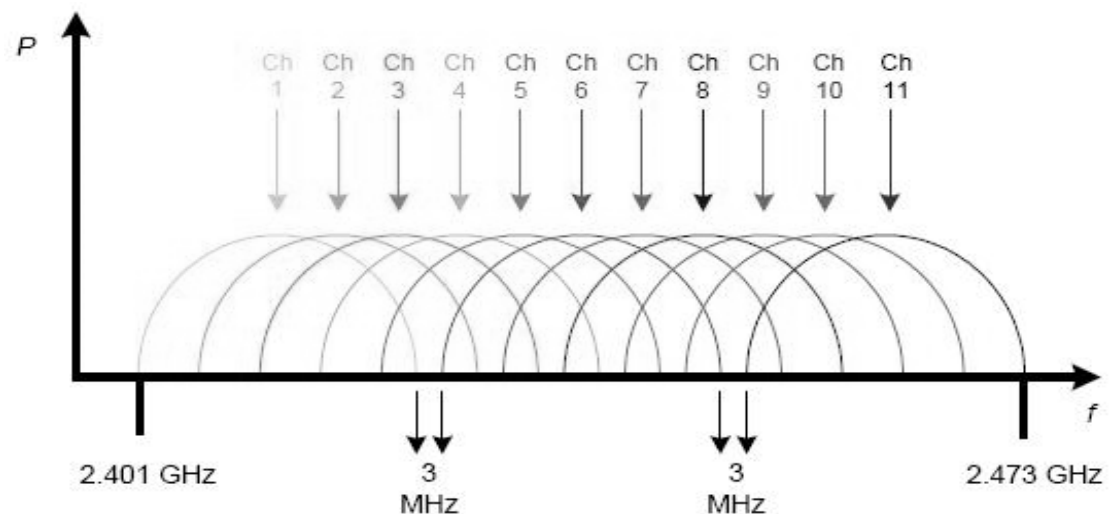

Gambar 2. Visualiasasi DSSS

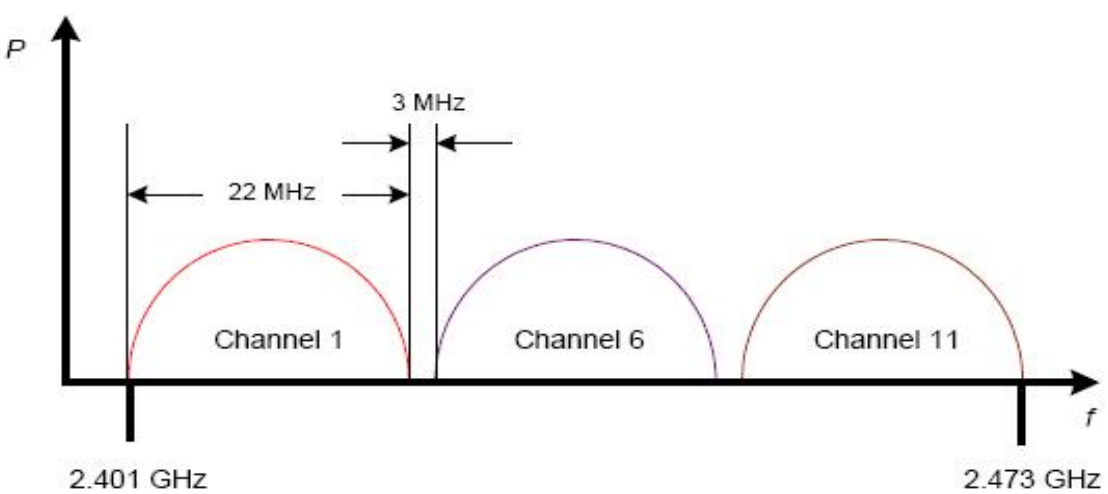

Gambar 3. Channel 1, 2, 3 tidak overlapping.

Direct sequence system menggunakan suatu definisi saluran yang lebih konvensional. Tiap saluran merupakan suatu band frekuensi yang bersebelahan yang lebarnya sebesar 22 $\mathrm{MHz}$. Misalnya, Channel 1 bekerja dari frekuensi 2,401 GHz sampai 2,432 GHz $(2,412 \mathrm{GHz} \pm$ $11 \mathrm{MHz})$, channel 2 bekerja dari 2,406 sampai $2,429 \mathrm{GHz}(2.417 \pm 11 \mathrm{MHz})$, dan seterusnya, seperti pada gambar 2 . 
Seperti pada channel 1 dan 2 yang overlap dengan suatu besaran yang signifikan. Penggunaan sistem DSSS dengan channel-channel yang bertumpang-tindih (overlapping channel) akan menimbulkan interferensi antar-sistem tersebut. Pada gambar 2 divisualisasikan terdapat jarak $5 \mathrm{Mhz}$ dari masing-masing frekuensi sentral (mis. saluran $1 \mathrm{f}$-sentral $=2,412 \mathrm{GHz}$ sedangkan saluran $2 \mathrm{f}$-sentral $=2,417$ dan seterusnya).

Dengan demikian channel-channelsebaiknya ditempatkan pada lokasi yang sama dan terpisah satu sama lain yaitu channel 1, 6 dan 11 tidak bertumpang-tindih; channel 2 dan 7 tidak bertumpang-tindih, dan seterusnya, seperti digambarkan di gambar 3. Teknik spread spectrum antara FHSS dan DSSS memiliki perbedaan cara dan metode, oleh karenanya pada kedua teknik tersebut memiliki keunggulan dan kelemahan tersendiri antara yang satu dengan yang lain. Beberapa hal yang dapat bandingkan, antara lain :

1) Interferensi narrowband

Keunggulan dari teknologi FHSS adalah resistensinya yang lebih besar terhadap interferensi narrowband. Sistem DSSS lebih mudah dipengaruhi oleh interferensi narrowband jika dibanding sistem FHSS karena sistem tersebut menggunakan band-band yang berdekatan dengan lebarnya $22 \mathrm{MHz}$, bukannya $79 \mathrm{MHz}$ seperti yang digunakan pada sistem FHSS.

2)Biaya

Biaya untuk mengimplementasikan DSSS jauh lebih rendah jika dibanding dengan biaya FHSS. Karena pada direct sequence untuk tiap peralatan memiliki channel frekuensi tersendiri sehingga komponen yang diperlukan lebih sederhana

\section{3)Co-lokasi}

FHSS memiliki kemampuan untuk menepatkan lebih banyak frequency hopping system secara bersamaan jika dibanding pada DSSS. Karena FHSS merupakan frekuensi yang memiliki agilitas tinggi dan memanfaatkan 79 channel diskrit, sehingga FHSS memiliki suatu keunggulan ko-lokasi, dibanding DSSS, yang hanya memiliki co-lokasi maksimum 3 titik akses (maksimum 3 channel frekuensi).

\section{4)Throughput}

Throughput DSSS masih lebih unggul daripada FHSS, karena DSSS memiliki maksimum 3 titik akses.

5) Kompatibilitas dan ketersediaan peralatan WECA (Wireless Ethernet Compatibility Alliance) melakukan pengujian atas peralatan WLAN dengan DSSS yang sesuai dengan standar 802.11b untuk menjamin bahwa peralatan semacam itu dapat bekerja bersama dengan piranti DSSS standar 802.11 lainnya.

Standar interoperasibilitas yang diciptakan oleh WECA yang sekarang pemakaiannya disebut sebagai Wireless Fidelity, atau Wi-Fi. Sedangkan untuk FHSS belum ada organisasi yang mau melangkah lebih jauh untuk melakukan semacam pengujian kompatibilitas seperti pada DSSS

Sejak tahun 2000, pemerintah Republik Indonesia telah mengalokasikan spektrum frekuensi radio untuk layanan akses nirkabel bidanglebar (Broadband Wireless Access, BWA) guna memenuhi kebutuhan layanan akses data dan Internet (Postel, 2006). Secara garis besar, penggunaan frekuensi BWA dapat dibagi menjadi dua bagian yaitu penggunaan frekuensi secara eksklusif di suatu wilayah layanan pada blok frekuensi tertentu, dan penggunaan frekuensi secara non eksklusif untuk suatu penyelenggara (Postel, 2008).

Detail dari kedua bagian tersebut adalah:

a. Bidang Frekuensi Eksklusif, yang meliputi :

1) bidang frekuensi $300 \mathrm{MHz}(287-294 \mathrm{MHz}, 310-324 \mathrm{MHz})$

2) bidang frekuensi $1.5 \mathrm{GHz}(1428-1452 \mathrm{MHz}$ dan $1498-1522 \mathrm{MHz})$ 
3) bidang frekuensi $1.8 \mathrm{GHz}(1780-1805 \mathrm{MHz})$

4) bidang frekuensi $1.9 \mathrm{GHz}(1880-1920 \mathrm{MHz}, 2010-2025 \mathrm{MHz})$

5) bidang frekuensi $2 \mathrm{GHz}(2053-2083 \mathrm{MHz})$

6) bidang frekuensi $2.5 \mathrm{GHz}(2500-2520 \mathrm{MHz}$ dan $2670-2690 \mathrm{MHz})$

7) bidang frekuensi $3.3 \mathrm{GHz}(3300-3400 \mathrm{MHz})$

8) bidang frekuensi $3.5 \mathrm{GHz}(3400-3600 \mathrm{MHz})$

9) bidang frekuensi $10.5 \mathrm{GHz}(10150-10300 \mathrm{MHz}$ dan $10500-10650 \mathrm{MHz})$

b. Bidang Frekuensi Non Eksklusif (Share used), yang meliputi :

1) bidang frekuensi $2.4 \mathrm{GHz}(2400-2483.5 \mathrm{MHz})$

2) bidang frekuensi $5.2 \mathrm{GHz}(5150-5350 \mathrm{MHz})$

3) bidang frekuensi $5.8 \mathrm{GHz}(5725-5825 \mathrm{MHz})$.

Spektrum frekuensi BWA yang berbasis eksklusif diatur pemanfaatannya melalui kebijakan pentarifan BHP (Biaya Hak Penggunaan) Frekuensi Radio yang besarannya ditentukan dalam Izin Stasiun Radio (ISR)

per kanal frekuensi. Sedangkan untuk bidang frekuensi $2,4 \mathrm{GHz}$, berdasarkan Peraturan Menteri Perhubungan No.2 Tahun 2005, telah diberlakukan izin stasiun radio yang melekat pada sertifikasi perangkat. Artinya bahwa penggunaan frekuensi radio di pita frekuensi 2400 $2483,5 \mathrm{MHz}$ dapat dilakukan oleh setiap pengguna secara bersama-sama (sharing) dengan syarat beroperasi memenuhi ketentuan teknis dan menggunakan perangkat yang disertifikasi oleh Ditjen Postel. Untuk bidang frekuensi $5,2 \mathrm{GHz}$ akan diusulkan izin kelas bagi semua pengguna dengan ketentuan sebagaimana pada bidang frekuensi $2,4 \mathrm{GHz}$, adapun untuk bidang frekuensi $5,8 \mathrm{GHz}$ sejak tahun 2000 telah dialokasikan untuk beberapa penyelenggara dengan penggunaan secara bersama (sharing). Bidang frekuensi $5,8 \mathrm{GHz}$ merupakan salah satu pita frekuensi yang diidentifikasi untuk "unlicensed band" di Amerika Serikat (UNII band) dengan pembatasan daya pancar yang ketat. Oleh karena itu, masyarakat di Indonesia seringkali salah pengertian dan beranggapan bahwa penggunaan frekuensi $5,8 \mathrm{GHz}$ tidak perlu izin. Hal itu didukung pula oleh ketersediaan perangkat dualband $2,4 \mathrm{GHz}$ dan $5,8 \mathrm{GHz}$ di pasaran sehingga menyebabkan timbulnya banyaknya penggunaan bidang frekuensi $5,8 \mathrm{GHz}$ secara ilegal (Postel, 2006).

Sebelum munculnya Peraturan Menteri Perhubungan Nomor 2 Tahun 2005, penggunaan suatu bidang frekuensi tertentu umumnya mengacu pada rekomendasi ITU yang berlaku secara internasional. Secara umum, penggunaan suatu bidang frekuensi di Indonesia harus memiliki izin alokasi frekuensi dari Direktorat Jenderal Pos dan Telekomunikasi. Sebelum tahun 2005, muncul kontroversi mengenai perlu tidaknya izin untuk penggunaan bidang frekuensi $2,4 \mathrm{GHz}$ di Indonesia. Pemerintah yang setuju dengan keharusan berizin bagi setiap pengguna frekuensi $2,4 \mathrm{GHz}$, menganggap izin diperlukan untuk menjaga kelestarian pemanfaatannya dan menjamin semua orang dapat memperoleh akses yang sama terhadap frekuensi dimaksud. Sementara itu, yang tidak setuju menilai penetapan izin tidak perlu. Sebab, hanya akan menghambat pemanfaatan frekuensi tersebut secara maksimal (Taba, 2004).

Pada awalnya, bidang frekuensi $2,4 \mathrm{GHz}$ di Indonesia hanya diperuntukkan untuk outdoor microwave link. Namun dengan ditemukannya teknologi direct sequence spread spectrum dan frequency hoping spread spectrum, frekuensi ini juga digunakan oleh penyedia jasa Internet, institusi pendidikan dan berbagai organisasi kemasyarakatan lainnya untuk keperluan akses Internet (data) berbasis nirkabel bagi pengguna di luar gedung, yang saat ini lagi marak. Maraknya penyelenggaraan jasa internet berbasis nirkabel (Wireless-LAN) tidak lepas dari langka dan masih mahalnya akses internet melalui kabel (fixed lined). Selain itu, maraknya penggunaan frekuensi $2,4 \mathrm{GHz}$ untuk akses Internet (data) nirkabel juga dipicu oleh perkembangan teknologi wireless access dan membanjirnya produksi perangkat telekomunikasi yang bekerja pada bidang frekuensi tersebut. Kemudian pemasangan dan pengoperasian sistem wireless mudah dilakukan, dengan kecepatan transmisi data yang tidak kalah dengan media transmisi kabel.

Dengan teknologi spread spectrum, teknologi ini memungkinkan satu bidang frekuensi dapat digunakan beberapa pengguna secara serempak pada saat yang sama. Namun, pengguna dalam suatu area baru dapat memanfaatkannya secara optimal bila semua 
perangkat yang dipakai pada area tersebut menggunakan daya yang terbatas dan seragam. Bila hal itu tidak diindahkan, misalnya dilakukan pembesaran daya pancar, dapat terjadi interferensi antar perangkat. Bila interferensi itu berlanjut karena pengguna ingin lebih unggul dari pengguna lainnya maupun karena kurangnya pemahaman terhadap keterbatasan teknologi 2,4 Ghz, frekuensi 2,4 GHz tersebut tidak dapat lagi dimanfaatkan secara optimal.

Frekuensi 2,4 Ghz juga digunakan untuk keperluan industri, ilmu pengetahuan dan kesehatan Konsekuensinya, penggunaan perangkat komunikasi radio atau telekomunikasi yang akan bekerja pada bidang frekuensi tersebut harus siap menerima gangguan dari perangkat ISM, sebagaimana tertuang dalam dalam Radio Regulation ITU (Taba, 2004). Terlepas dari beberapa perangkat wireless yang bekerja pada frekuensi 2,4 Ghz, penelitian yang penulis lakukan dibatasi pada penggunaan teknologi WiFi atau WLAN, karena teknologi ini mengalami perkembangan yang pesat sejalan dengan tingkat kemajuan teknologi informasi khususnya dalam media transfer data secara wireless yang membutuhkan bandwith yang besar. Seperti yang kita ketahui bahwa teknologi WiFi sudah masuk pada standart 802.11n dan WiMax.

\section{SYARAT TEKHNIS PITA FREKUENSI $2,4 \mathrm{GHz}$}

Dengan pembebasan frekuensi 2,4 GHz oleh pemerintah, para pengguna frekuensi 2,4 Ghz harus mengikuti aturan-aturan yang tertuang dalam Kepmen No.2 Tahun 2005 pasal 6 mengenai persyaratan teknis penggunaan pita frekuensi $2,4 \mathrm{GHz}$ diantaranya :

a. Effective Isotropically Radiated Power (EIRP) merupakan hasil perkalian antara daya yang dikeluarkan ke antenna dengan penguatan antenna, relative terhadapa antena isotropic pada suatu arah tertentu (penguatan mutlak atau isotropic) maksimum untuk penggunaan outdoor sebesar 4 Watt $(36.02 \mathrm{dBmW})$ dan untuk penggunaan indoor sebesar $500 \mathrm{~mW}(27 \mathrm{dBmW})$.

b. Daya pancar perangkat ( $T X$ Power) merupakan daya rata-rata perangkat yang dicantumkan pada saluran transmisi antenna maksimum $100 \mathrm{~mW}$.

c. Emisi diluar pita (out of band emission) maksimum adalah $-20 \mathrm{dBc}$ per $100 \mathrm{kHz}$.

Kemudian pasal 7 dan 8 mengenai sertifikasi alat dan perangkat yang bekerja pada frekuensi 2,4 GHz.Sehingga jika semua pengguna frekuensi 2.4 Ghz mengikuti aturan-aturan seperti atas, tingkat interferensi antar pengguna dapat ditekan sehingga tidak mengakibatkan kejenuhan dan kepadatan traffic bandwidth pada pita frekuensi 2,4 Ghz.

\section{INTERFERENSI}

Selain memahami bagaimana cara kerja tiap teknologi, juga penting untuk memahami bagaimana masing-masing teknologi berinteraksi dalam lingkungan yang homogen dan heterogen. Jaringan Wi-Fi yang menggunakan channel sama atau menggunakan channel yang tumpang tindih akan tetap berjalan karena memilki teknologi algoritma penghindaran tabrakan (collision avoidance algorithm), tetapi throughput setiap jaringan akan berkurang. Gangguan dari cordlessphone $2,4 \mathrm{GHz}$ bisa sepenuhnya menghentikan jaringan Wi-Fi, bahkan jika menggunakan cordlessphonesebagai lawan FHSS DSSS. Hal ini sebagian disebabkan oleh saluran yang lebih luas (5 hingga $10 \mathrm{MHz}$ ) juga karena daya yang lebih tinggi dari sinyal telepon nirkabel.

Sebuah FHSS telepon nirkabel yang melompat ke tengah-tengah channel Wi-Fi dapat mengganggu transmisi $\mathrm{Wi}-\mathrm{Fi}$, yang menyebabkan perangkat $\mathrm{Wi}-\mathrm{Fi}$ melakukan pengulangan transmisi. Dengan bantuan Wi-Spy dari Metageek dengan Chanalyzer dapat memberikan visualisasi wireless dalam tiga dimensi (frekuensi, amplitudo, dan waktu). Dengan visualiasi 3 dimensi Chanalyzer kita dapat lebih mudah menandai gangguan-gangguan yang ada. 


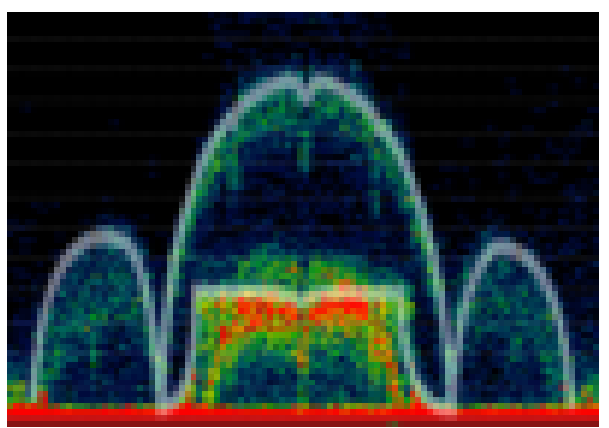

Gambar 4. Visualisasi WiFi

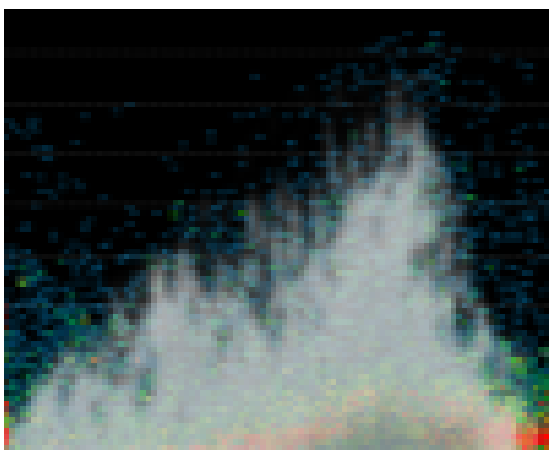

Gambar 5. Visualisasi Microwave

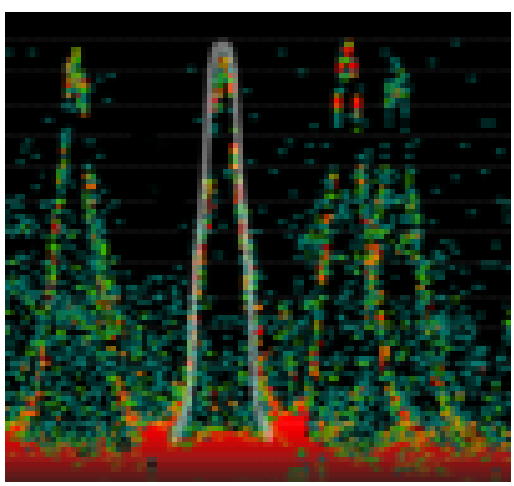

Gambar 6. Visualiasi Cordless Phone

Dari penjelasan diatas, beberapa hal yang akan menyebabkan interferensi didalam frekuensi $2,4 \mathrm{GHz}$ antara lain :

1) Penggunaan perangkat WLAN yang mempunyai daya melebihi daya yang diijinkan yaitu maksimum $100 \mathrm{~mW}$.

2) Penggunaan perangkat WLAN yang belum tersertifikasi oleh lembaga berwenang, sehingga kwalitas dari perangkat WLAN tidak sesuai yang diijinkan.

3) Teknologi perangkat WLAN yang tidak memiliki kemampuan untuk mengurangi interferensi, contohnya teknologi collision avoidance algorithm.

4) Penggunaan channel dari band ISM yang tidak diatur dengan bagus sehingga overlapping.

Untuk meminimalisasikan interferensi, pada perancangan jaringanW-LAN harus dilakukan pengendalian terhadap 5 parameterOhrtman, 2003)., yaitu :

1) Channel yang digunakan,

2) Jarak,

3) Level daya output perangkat, 
4) Antena

5) Protokol atau standart yang digunakan.

Guna menekan interferensi frekuensi 2,4 Ghz khususnya untuk pemanfaatan WLAN atau WiFi maka perlu dilakukan langkah-langkah nyata mengacu pada 5 parameter yang telah disebutkan diatas. Langkah-langkah ini, antara lain :

1) Sebelum pemasangan perangkat wireless $2,4 \mathrm{Ghz}$ perlu dilakukan terlebih dahulu "site survey", untuk menganalisa potensi gangguan yang mungkin terjadi.

2) Melarang penggunaan perangkat wireless yang berpotensi mengganggu, seperti Cordlessphone 2,4 Ghz

3) Menggunakan perangkat WLAN yang telah tersertifikasi, dan mempunyai kemampuan "noise immunity"

4) Menggunakan antenna directional dan mempunyai nilai SWR 1:1.5

5) Diperlukan BPF (Band Pass Filter) yang mempunyai kemampuan menekan interferensi dan menaikkan performa atau kualitas perangkat.

6) Jika dalam instalasi pernagkat WLAN memerlukan kabel jumper, maka kabel jumper harus memiliki impedansi 50ohm, dengan loss kabel yang kecil.

7) Jika beberapa langkah diatas telah dilakukan tetapi interferensi tidak dapat ditekan atau jika kita berada pada daerah yang sudah congested atau padat frekuensi ISM nya, maka ada suatu langkah yang bisa dilakukan yaitu dengan menggunakan teknologi SuperChannel.

\section{SUPERCHANNEL}

Salah satu metode cepat untuk mengatasi masalah interference adalah dengan memanfaatkan kemampuan Superchannel dari perangkat wireless. Dibanding dengan menggunakan penguaat daya atau booster $2,4 \mathrm{GHz}$, penggunaan Superchannel lebih bijaksana, Salah satu perangkat wireless dengan chipset Atheros AR5413 yang memiliki Superchannel adalah mini-PCI R52, R52H, CM9 yang merupakan produk dari mikrotik. Rentang frekuensi Superchannel 2,4 Ghz mulai dari 2192Mhz - 2539Mhz. Memang rentang frekuensi dalam superchannel ini illegal untuk beberapa negara, seperti Indonesia, tetapi banyak penyedia jasa akses internet atau ISP menggunakan kemampuan superchannel ini untuk media komunikasi data, baik untuk distribusi ke pelanggan atau untuk jaringan backbone ISP. Dengan kemampuan superchannel yang ada pada suatu wirelesss card, dan ditunjang dengan kemampuan software wireless yang baik seperti mikrotik,maka juga bisa didapatkan kemampuan wireless Turbo, throughput data rate dari perangkat wireless lebih besar,

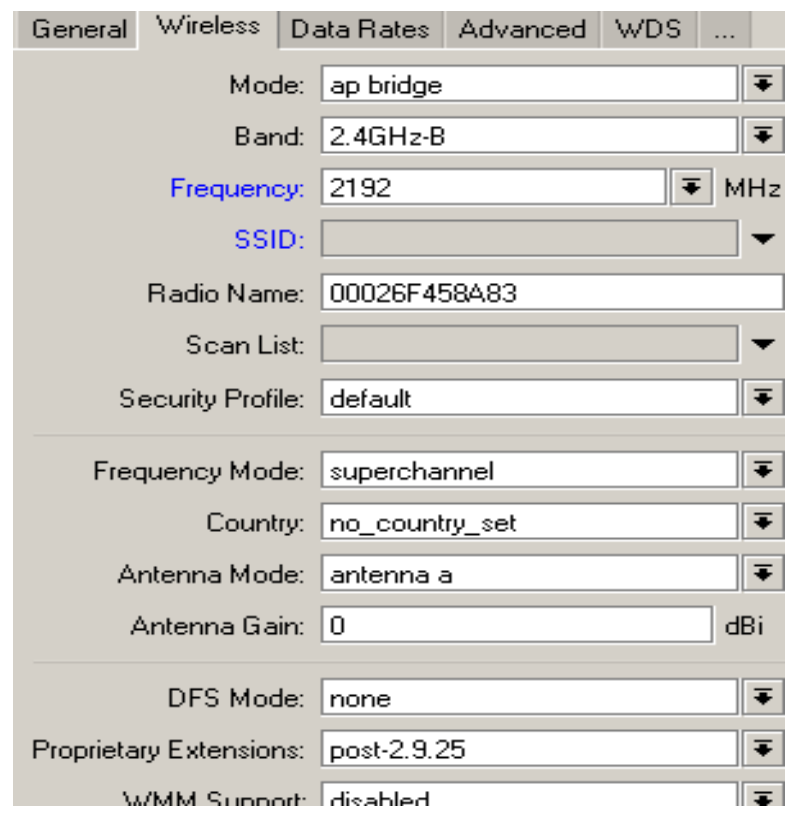

Gambar 7. Pengaturan Superchannel pada Mikrotik 


\section{KESIMPULAN}

Dari beberapa hal yang telah dijabarkan diatas, dapat ditarik kesimpulan bahwa dengan pembebasan frekuensi $2,4 \mathrm{GHz}$ membawa dampak yang positif bagi perkembangan teknologi informasi khususnya dalam teknologi media transfer datanya. Tetapi dampak negatif juga muncul, diantaranya banyak pengguna WLAN menggunakan penguat daya dan perangkat yang tidak tersertifikasi sehingga membuat interferensi pada frekuensi ISM 2,4 Ghz. Alhasil membuat kualitas, troughput dari perangkat WLAN berkurang, dengan keadaan yang seperti ini, masih saja ada pengguna WLAN menambah lagi daya pancar dari pernagkat WLAN, tentunya sudah pasti apa yang terjadi, frekuensi yang sudah interferensi menjadi lebih interferensi.

Solusi sementara yang bijak adalah dengan tanpa menambah daya pancar dari WLAN, menggunakan perangkat WLAN yang tersertifikasi, memanfaatkan kemampuan dari beberapa perangkat wireless yang dapat berkerja pada frekuensi Superchannel. Perangkat WLAN yang mempunyai kemampuan superchannel diantaranya miniPCI R52, R52, CM9, XR2, kemudian operating sistem yang mendukung Superchannel salah satunya Mikrotik. Dengan channelchannel selain 11 channel standart ISM, diharapkan mampu mengatasi interferensi frekuensi 2,4 Ghz dengan cepat, sebelum dilakukan langkah lain yang akan menjadi solusi jangka panjang dalam mengatasi interferensi frekuensi $2,4 \mathrm{GHz}$, artinya metode ini bukan metode permanen.

\section{DAFTAR PUSTAKA}

Geier Jim. (2005). Minimize WLAN Interference. http://www.wifi-planet.com James Trulove. (2002). Build Your Own Wireless LAN. McGraw-Hill, Inc Kepmen No.2 Tahun 2005, http://www.depkominfo.go.id Metageek (2008). Interference Identification Guide. http://www.metageek.net Pangera, Abas. (2009). Perbandingan FHSS dan DSSS. Jurnal DASI. AMIKOM Yogyakarta. Penataan Spektrum Frekuensi BWA, http://www.depkominfo.go.id.

Woodings, Ryan dan Gerrior, Mark. (2005). Avoiding Interference in the 2.4-GHz ISM Band. Cypress Semiconductor

http://www. wirelesslan.com

http://www.ieee.org

http://www.routerboard.com

http://www.mikrotik.com 